\title{
A Study on Modern Trends in Cruise Ship Industry
}

\author{
Pulla Suresh \\ Institute of Hotel Management, Hyderabad.
}

\begin{abstract}
In the course of recent years, the overall interest for the voyage the travel industry has posted some of the most significant additions inside the travel industry segment. The consistent dynamism in journey movement, additionally in light of the fact that the expanding number of countries that incorporate travels, as a key item for the travel industry advancement. This new investigation examines subjects simply like the current flexibly and interest for travels qualities and patterns. New component incorporates the association among objections and journey lines breaking down the key elements like enactment, advancement, and thus the financial effect of travels. This presents current patterns in the business regarding advancement, wellbeing and security, manageability and distinguishes the primary lines.
\end{abstract}

Keywords:- Travel Industry, New component, Advancement, Enactment, Security.

\section{INTRODUCTION}

Every year new patterns rise in the cruising business that make ready for the eventual fate of cruising. In 2019, we saw an expanded interest for off in unexpected direction objections, tech-driven highlights on ships, and an expansion in working travelers - to give some examples. In 2020, a major point of convergence of the business will be on making cruising all the more earth reasonable, putting more significance on mindful the travel industry, the reduction in the generational hole in cruisers, and more choices for solo voyagers. The development of the overall voyage industry is unwavering, with the freshest Cruise Lines International Association (CLIA) report showing that 2019 will be one more year for the record books, it's normal that 30 million explorers will have taken to the world's streams and oceans before 2020 moves around, up $6 \%$ on 2018. Cruiseliners isn't any sluggard when it includes riding the waves, with the locale being the fourth-biggest source market inside the world for worldwide cruising. To oblige the ever-extending client base, journey lines are getting progressively innovative and trial in their contributions.

$>$ Objectives

- Knowing the latest tendency going on in cruise lines

- Knowing modernization about the cruise lines

- How the operations are carried out in cruise ships

- What is the technology used in cruise galley

- What are the new trends followed in waste management

\section{Cruise lines make strides to lower Environmental Impact:}

With global warming a hot topic and growing awareness about the effects of tourism on local communities and the planet as a whole, cruise lines started to take serious action to reduce their environmental impact, with plans to expand those efforts into 2020 and beyond. Hurtigruten has already eliminated all unnecessary singleuse plastics, and most lines have announced plastic bans, starting by eliminating plastic straws and/or water bottles.

As of January 2020, the Maritime Agency has established a reduction in the cut of the oil used for shipments that work outside the divergence control zone assigned to $0.50 \% \mathrm{~m} / \mathrm{m}$. This is to radically reduce the amount of sulfur oxides emitted by ships and is intended to bring great benefits to the world for well-being ecosystems, especially for residents who live near ports and drifts. Since then, this evolving enactment needs have increased interest in improving items for the zero discharging fleet and have helped meet global goals.

\section{Young Blood:}

Enter millennial-driven brand $\mathrm{U}$ by Uniworld, which will have two waterway ships - The An and The B - in Europe in 2020, and keeping in mind that the first 18-40 age limit has been rejected, the brand's contributions are still exceptionally curated for this crowd: think yoga studios, an Ice Bar including neighborhood DJs and quiet discos, Pop-Art on the dividers and mixology classes between Visits where you can pick your own experience at each port, which may incorporate a Van Gough painting workshop in Arles or a preparing class in food-driven Lyon.

\section{$>$ Going green:}

Administrators are exploring the change to cleaner fuel options with lower Sulfur content, and by 2025 it's anticipated that the business will highlight 25 boats controlled by fluid gaseous petrol (LNG): from 2020, Carnival will utilize the super-cool fuel to control a 5,200traveler transport, making it the principal journey vessel in North America to utilize LNG. This year, Norwegian voyage line Hurtigruten propelled the business' first crossover fueled boat, impelled by electric engines and inward ignition motors.

\section{Well and good:}

Wellness tourism is now so main stream that most Cruise liners come equipped with state-of-the-art fitness centers, day spas, medical spas and restaurants dishing up healthful cuisine that is low in calories and high in antioxidants. 


\section{$>$ Onboard Smart tech:}

Cruise lines has adopted the technology for cruise travelers-including key chains, bracelets, necklaces, apps and more in order to provide high personalized travel experience while on and off the ship. The ship contains an NFC chip and a Bluetooth Low Energy antenna. With these two pieces of technology the ships system can recognize guests as they move about. It can then give them information on upcoming activities, opportunities, and experiences going on around the ship. Guests on the Edge can upload a selfie to the app, and the company's facial recognition software will automatically check them into the cruise, allowing them to bypass long check-in lines. Cruisers can see their itinerary, and link their reservations with other guests' to make plans together onboard. The app also allows passengers to see entertainment and dining options, and information about activities on the ship. Guests can open their doors and adjust the thermostat in their rooms through the app.

\section{Cruise Ship Kitchens use Technology for Better Experiences:}

Kitchen In the 21st century, it makes no sense for cruise ships to stay cut off from technology that people on land are so used to. This especially makes sense in cruise ship kitchens where meals for thousands of guests must be prepared and served several times a day. In the galley technology has pervaded many areas. Stand mixers replace hand mixers, large vats maintain temperature and highly accurate machines help reduce human intervention for techniques such as sous vide cooking. Many cruise ships are now gearing their new technology towards energy efficiency with speed. They use automatic systems that clean pans within two minutes without the use of chemicals. Its combi steamer even has digital displays that note the amount of energy and water used during a cooking process for better efficiency and sustainability.

\section{$>$ New Trends in Waste Management:}

Voyage ships involve far however $1 \%$ of the overall oceanic network journey lines are at the front line in creating capable, natural practices and imaginative advancements that lead in ecological stewardship. The voyage business takes an interest in territorial sea arranging endeavors with sea partners and gives direct information and input to manage sea the board difficulties and consequently the reasonable utilization of seas. Journey lines cautiously follow squander the executives and reusing rehearses (connection to Squander The board Strategy) to stop squandering in seas. Because of the endeavors of profoundly prepared waste administration experts locally available, some journey ships repurpose $100 \mathrm{pc}$ of the waste created installed - by diminishing, reusing, giving, reusing, and changing over waste into energy.

\section{$>$ Operations:}

Journey ships involve under $1 \%$ of the business vessels around the world; the centrality of excursion industry in the movement business and the overall economy can't be put down, with a conspicuous complete of 30 million ocean journey voyagers stretched out in 2019 .
- Social media is generally speaking constantly related even unfastened consistently sharing Instagram feeds and Face book posts from traveling experience while locally accessible.

- Many journey lines have introduced usage of arm groups or pieces of jewelry for voyagers to open their rooms, purchase organizations locally accessible and various others.

- The Voyage Lines Industry Affiliation (CLIA), as the world's greatest excursion industry trade alliance, has been one of the business bundles which conveyed and maintained the latest invigorated guidelines on advanced security introduced ships.

- Cruising considers solo travel, as it allows to explorers to interface with various adventurers. Cruise crusades that engage explorers to experience different travel openings and watch remarkable normal marvels like Aurora Borealis or Icy untamed life.

- The journey industry fills in as a veritable model for the maritime division in the field of ladies intrigue. While women mariners build up about $2 \%$ of gatherings around the world.

- As set value is expanding growing care in business division, women's intrigue is needed to turn out to be further in cruising, as a tremendous aspect of the ocean portion which hopes to achieve a more unmistakable gender in ships.

\section{CONCLUSION}

The study mainly focuses on trends and rapid growth in cruise Industry; it is one of the fastest and most profitable segments in the world. In many ways the industry reflects the strengths that have emerged relentless growth in globalization. As a result there is an increased innovation in developing cruise facilities .The cruise Industry benefits with high degree of loyalty, it provides innovative vacation to millions of people which they will never forget in their life time. This cruise Industry committed to social, economical and environmental well being to the society.

\section{REFERENCES}

[1]. https://expediafranchise.com/blog/2020-cruise-trends/

[2]. https://www.delicious.com.au/travel/international/gall ery/biggest-cruising-trends-2020/kqlxtbyy

[3]. https://www.usatoday.com/story/travel/cruises/2020/0 1/01/2020-cruise-trends-more-private-islands-themecruises-expeditions/2785049001/

[4]. https://www.cruising.org.au/Tenant/C0000003/00000 001/CLIA \%202019\%20State\%20of\%20the\%20Indust ry.pdf

[5]. http://www.acclaindia.com/success-stories/howcruise-ship-kitchens-use-technology-for-betterexperiences

[6]. https://www.nytimes.com/2019/11/24/travel/techcruises.html

[7]. https://www.researchgate.net/publication/282848343_ Cruise_Ship_Marine_Operations/link/562389e508aea $35 f 26865 \mathrm{bc} 3 /$ 
[8]. http://www.imo.org/en/OurWork/Safety/Regulations/ Pages/PassengerShips.aspx

[9]. https://www.prnewswire.com/news-releases/newwaste-management-technologies-for-cruise-shipindustry-promoting-sustainability-300995904.html

[10]. https://blog.winnowsolutions.com/cruise-industrytrends-in-2020-and-why-they-matter

[11]. https://safety4sea.com/cm-9-cruise-trends-we-willsee-in-2019 